\title{
The Coordination Chemistry in the Antifungal Effect of Tin(IV)-Bis(Pyrimidin-2-YIthio)Alkane Derivatives
}

\author{
Fernanda Andrade Mendonça ${ }^{1}$, Geraldo José da Silva Junior ${ }^{2}$, José Roberto da Silveira Maia ${ }^{1, *}$, \\ Onkar Dev Dhingra², Rosimeire Coura Barcelos ${ }^{1}$ \\ ${ }^{1}$ Departamento de Química, CCET / Universidade Federal de Viçosa, 36570-900, Viçosa, MG, Brasil \\ ${ }^{2}$ Departamento de Fitopatologia, CCA/ Universidade Federal de Viçosa, 36570-900, Viçosa, MG, Brasil
}

Email address:

jrsmaia@outlook.com (J. R. D. S. Maia)

To cite this article:

Fernanda Andrade Mendonça, Geraldo José da Silva Junior, José Roberto da Silveira Maia, Onkar Dev Dhingra, Rosimeire Coura Barcelos. The Coordination Chemistry in the Antifungal Effect of Tin(IV)-Bis(Pyrimidin-2-Ylthio)Alkane Derivatives. American Journal of Applied Chemistry. Vol. 3, No. 2, 2015, pp. 77-82. doi: 10.11648/j.ajac.20150302.17

\begin{abstract}
High productivity of agriculture goods is closely associated with the use of fungicides to reduce losses caused by the fungal plant diseases. However, appearance of resistant population of pathogens to several commercial fungicides is a common phenomenon that requires control. There is, therefore, need for developing novel fungicide compounds that are environmentally safe with low toxicity to wild life and humans. In this study novel organotin(IV) derivatives of bis(pyrimidin-2-ylthio)methane (ptm), bis(pyrimidin-2-ylthio)ethane (pte) and bis(pyrimidin-2-ylthio)hexane (pth) were tested against phytopathogens to evaluate their activity as potential fungicides. The bis(pyrimidin-2-ylthio)alkanes were not active in contrast with the organotin(IV) derivatives. The 5-coordinate triphenyltin(IV) derivatives were the most active compounds in a wide range of concentration. This study shows that the microorganisms were susceptible to the acid character of the organotin(IV) precursors.
\end{abstract}

Keywords: Antifungal, Organotin, Bis (Pyrimidin-2-Ylthio) Alkanes, Storage Fungus, Fungicide, Phytopathogens

\section{Introduction}

Modern developments in technology and the continuous increasing in the productivity of agricultural products are closely associated with the intensive use of fungicides, despite the wide occurrence of fungal plant disease. Several types of fungicide molecules with different mode of action are commercially available. At the same time, there is a constant danger from inevitable appearance of resistant populations of pathogens, resulting in the failure of crop protection.

This problem is further aggravated if efficient antifungal compounds are not developed as an alternative to replace the "failed fungicides" [1-6]. A number of fungicides currently available are considered unsafe to the environment [7]. It is essential to discover novel antifungal compounds environmentally friendly to improve the quantity and the quality of agricultural goods. Organotin compounds are acknowledged as fungicides, bactericides as well as antitumor drugs and have been attracting interest to inorganic chemists in the last decades [8-15].

Continuing with our research program concerning the synthesis, characterization and antimicrobial activity of coordination compounds, this study reports on the in vitro antifungal assay of tin(IV)-bis(pyrimidin-2-ylthio)alkanes derivatives as well as on an attempt to correlate that with chemical aspects concerning the coordination chemistry field. These organotin(IV) compounds were previously characterized by our research group, and recently their bioassay have been carried out on microorganisms.

\section{Results and Discussion}

Several basic plant pathology methods are available to investigate the antifungal activity of substances [16]. Irrespective of the technique used in this study to determine the fungicidal effect, fungal growth was inhibited at several concentrations. The site in the microorganisms where the biochemical interactions occurs is a challenge to any researcher in the field. Nevertheless, the chemical properties of a molecule or a coordination compound may give an insight into the relationship of that with the antimicrobial effect. For instance, substituent groups have proven to be important chemical features of bioactive substances to a broad spectrum 
of microorganisms [17]. The significance of substituent groups to biological activity is revealed by N-heteroarylbenzylamines and the corresponding Schiff base derivatives ( $\mathrm{p}-\mathrm{RPhCH}=\mathrm{NR}$; $\mathrm{p}-\mathrm{RPhCH}=\mathrm{NR}^{\prime}, \mathrm{R}=\mathrm{H}, \mathrm{CH}_{3}$; R' $=$ pyridin-2-yl, pyrimidin-2-yl, benzothiazol-2-yl) [18]. These compounds are active against strains of Gram-positive and Gram-negative bacteria, presenting MICs (Minimum Inhibitory Concentration) in the range of 32 to $256 \mathrm{mg} \mathrm{L}^{-1}$. Similarly, the bioassay of the amine precursors on phytopathogens showed inhibition of 3.6 to $100 \%$ at the concentration range of 6.25 to $100 \mathrm{mg} \mathrm{L}^{-1}$. In this case, these amine compounds were the most active against $R$ solani in comparison to the corresponding Schiff base derivatives. The opposite effect happened to $D$ graminea. The increasing activity of these compounds was attributed to their chemical properties, either the presence of a biphenyl ring moiety or a large $\pi$-conjugated system on the molecules [18]. Fig. 1 shows the chemical structures of the bis(pyrimidin-2-ylthio)alkanes.

Organotin(IV) compounds are also significant in the growth of microorganisms. It has been reported that compounds such as di- and trialkylorganotin(IV) derivatives of Schiff bases increased the toxic effect on Bacillus subtilis and Staphylococcus aureus [19]. Triorganotin(IV) compounds show antitumoral effect in vitro as well $[8,9]$.

As shown in Fig.1, there is structural differences among the bis(pyrimidin-2-ylthio)alkanes regarding the carbon chain size between the sulfur atoms. This chemical property is not relevant to the antimicrobial effect of the free ligands, regardless of the chain size, because they were not active. However, upon coordination to the metal center, the free bis(pyrimidin-2-ylthio)alkanes are activated.

\subsection{Antifungal Activity}

The antifungal data of the organotin(IV)bis(pyrimidin-2-ylthio)alkanes demonstrate that not all of the compounds have inhibited the growth of the fungal species. The results show clearly that the tri- and tetrachloride tin(IV) derivatives $\{3,4,7,8,12$ and 13 , see (a) Graph 1$\}$ are not fungi toxic as well as the free ligands even at the higher concentrations tested $\left(1000\right.$ and $\left.3000 \mathrm{mg} \mathrm{L}^{-1}\right)$. This antifungal data are in contrast with the results of the other organotin(IV) compounds tested.<smiles>c1cnc(SCSc2ncccn2)nc1</smiles>

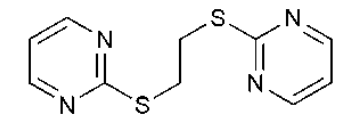

bis(pyrimidin-2-y|thio)methane

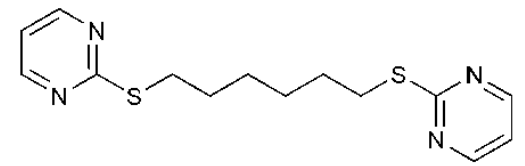

1,6-bis(pyrimidin-2-ylthio)hexane

Figure 1. Molecular structure of bis(pyrimidin-2-ylthio)alkanes.

Complex-1 and 5 inhibited fungal growth completely at the concentration of $80\left(\right.$ method B) and $100 \mathrm{mg} \mathrm{L}^{-1}$ (method A). The fungal inhibition by complex- 9 and 10 occurred at higher concentration, $400 \mathrm{mg} \mathrm{L}^{-1}$ (method B) to all fungi species, and at $300 \mathrm{mg} \mathrm{L}^{-1}$ (method A) to C. gloesporioides only see (b) Graph 1$\}$. These concentrations are probably close to the MIC values because the derivatives 1 and 5 were inactive at $50 \mathrm{mg} \mathrm{L}^{-1}$ and complex-9 and 10 inactive at 100 $\mathrm{mg} \mathrm{L}^{-1}$ to all fungi tested.

The standard range of concentration in which organotin(IV)-Schiff bases are active against microorganinsms is 50 to $250 \mathrm{mg} \mathrm{L}^{-1}[20,21]$. This range of concentration is an outstanding result, although marketable fungicides and bactericides such as Tetracycline, Chloramfenicol, Kanamycin, Cefazolin Sodium and Cefotaxime show growth inhibition at lower concentration (3.12 $\mathrm{mg} \mathrm{L}^{-1}$ ) [22]. The triphenyltin(IV) derivatives of ptm and pte, complex-1 and 5, were the most active compounds showing activity below $150 \mathrm{mg} \mathrm{L}^{-1}$, which is a good result in comparison to the range of organotin(IV) derivatives of Schiff bases as well as organic fungicide molecules such as pyridin-2-yl, pyrimidin-2-yl and benzothiazol-2-yl [18, 20].

\subsection{Coordination Chemistry}

Although the mechanism of action regarding the fungi toxicity of these organotin(IV)-bis(pyrimidin-2-ylthio)alkanes is still uncertain, a correlation between the chemical aspects of these organotin(IV) compounds and the antifungal effect can be postulated by the bioassay data.

The toxic effect of the ligand upon coordination - The bioassay revealed that the free ligand is inactive against the microorganisms tested. However, the number of carbon atoms from the alkyl fragment of the ligand appears to influence the fungal growth upon coordination. As the number $n$ reduces in the $\left(\mathrm{CH}_{2}\right) n(n=1,2,6)$ moiety of the coordinated ligand, the corresponding compound becomes more active. That is the case of the triphenyltin(IV) derivatives, complex-1 and 5 ( $n=$ 1 and 2 respectively), which are active at the concentration of $80 \mathrm{mg} \mathrm{L}^{-1}$ (method B). By adding more carbon atoms to the $\left(\mathrm{CH}_{2}\right) n$ group, complex-9 and $10\{n=6$, see (b) Graph 1$\}$, the concentration increases to $400 \mathrm{mg} \mathrm{L}^{-1}$ (method B). A slight different pattern happens to the diphenyltin(IV) derivatives. Complex-2 $(n=1)$ was fungi toxic at the concentration of $1000 \mathrm{mg} \mathrm{L}^{-1}(\operatorname{method} \mathrm{A})$ and complex-6 $(n=2)$ at $500 \mathrm{mg} \mathrm{L}^{-1}$ (method A) while complex-11 $(n=6$, see Graph 1) was inactive to all fungi tested. As the $n$ value in the $\left(\mathrm{CH}_{2}\right) n$ fragment increases the inhibitory concentration of these derivatives decreases.

The coordination mode of the ligand to a metal center is also a chemical feature that might influence the biochemical interactions on microorganisms. In complex-9, the ligand is monodentate towards the metal but in complex-1, 2, 5 and 10 the ligands are acting in a bridging bidentate mode (see Fig.2). Among these compounds, only complex-9 has the $p$ th ligand with uncoordinated loose end. Because of that, the difference in coordination mode of this ligand towards the metal center is supposed to show a contrasting biochemical interaction. However, a comparison of the resulting activity between 
complex-9 and 10 show that these chemicals were fungi toxic at the same concentration. Consequently, the coordination mode of the bis(pyrimidin-2-ylthio)alkanes have no influence on the fungicidal effect of the organotin(IV) compounds tested. Nevertheless, the bioassay data reveals that the activity of the ligands are related to their coordination to the tin(IV) center and that the size of the alkane chain has an influence on the fungi toxic effect.

The geometry and the metal-ligand bond - The bioassay data show that all 5-coordinate triphenyltin(IV) complexes (1, 2, 5, 9, and 10, see Fig.2) are active against the fungal species tested, while the 6-coordinate diphenyltin(IV) ones (3, 4, 7, 8, 11, 12, and 13, see Fig.3 and 4) are inactive, except complex-6.
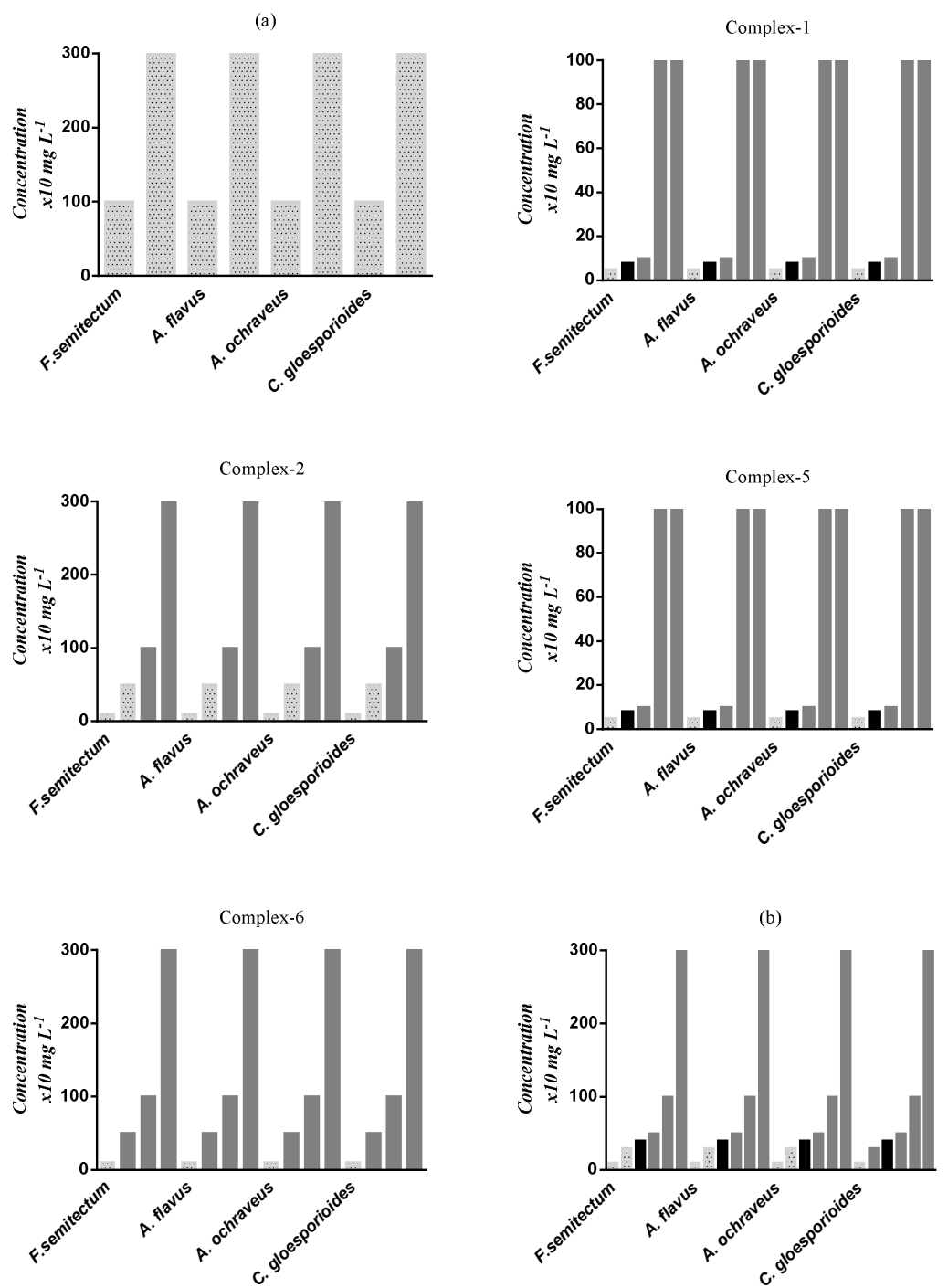

The biological activity of organotin(IV) compounds are recognized in many geometric arrangements. In these compounds the tin(IV) atom is usually bonded to an oxygen, nitrogen or sulfur atoms from the ligand. Several organotin(IV) compounds that show antitumor activity seems to have a tin(IV)-oxygen bond as a common chemical feature [8]. Similarly, tin(IV)-nitrogen and tin(IV)-sulfur bonds appears to be the common chemical features of fungicides and bactericides [11, 23-25]. Not only the tin(IV) derivatives but also transition metal complexes in general play an important role in biological activity. A number of octahedral first-row transition metal complexes are recognized to show antifungal activity [26].

(b)

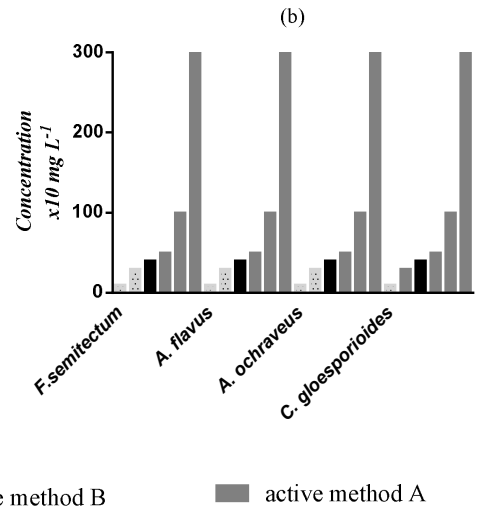

Graph 1. Antifungal data of bis(pyrimidin-2-ylthio)alkanes and tin(IV) derivatives.

Method B: active is equal to $0 \% p g$; inactive is equal to $100 \%$ pg. (a): ptm; pte; pth and complexes: 3 . [ $\left.\mathrm{Sn}_{2} \mathrm{Cl}_{6} \mathrm{Ph}_{2}(p t m)\right] ; 4$. $\left[\mathrm{Sn}_{2} \mathrm{Cl} l_{8}(p t m)\right] . \mathrm{H}_{2} \mathrm{O} ; 7$.

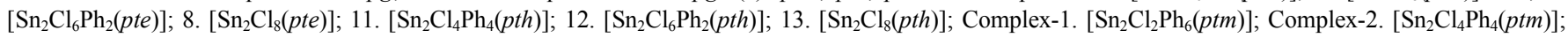
Complex-5. [ $\mathrm{Sn}_{2} \mathrm{Cl}_{2} \mathrm{Ph}_{6}($ pte $\left.)\right]$; Complex-6. [ $\mathrm{Sn}_{2} \mathrm{Cl}_{4} \mathrm{Ph}_{4}($ pte $\left.)\right]$; (b): Complex-9. [SnClPh 3 (pth)] and complex-10. [ $\mathrm{Sn}_{2} \mathrm{Cl}_{2} \mathrm{Ph}_{6}($ pth $\left.)\right]$. 


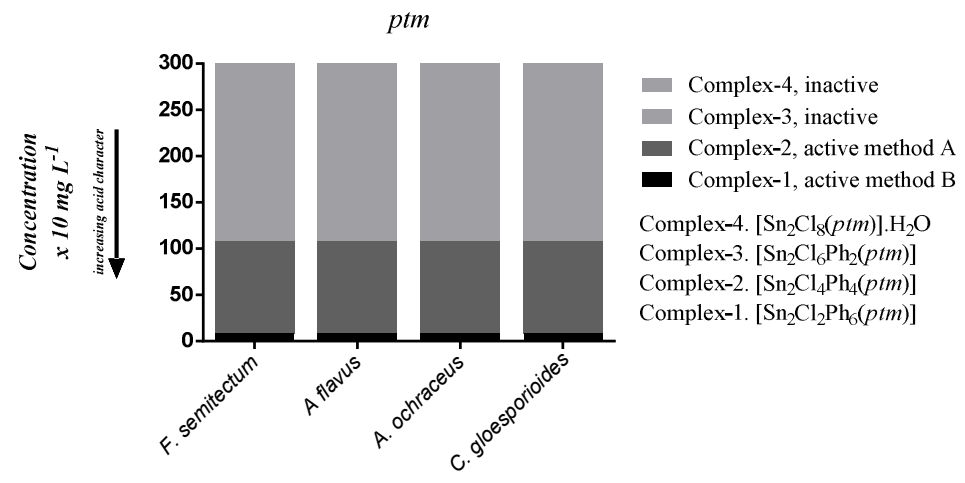

Graph 2. Acid character effect of the organotin(IV) complexes on fungi growth.

Considering that the $\mathrm{Zn}(\mathrm{II})$ - and $\mathrm{Mn}(\mathrm{II})$-sulfur are typical bonds of the marketable fungicides Zineb (Zinc ethane-1,2-diylbis(dithiocarbamate) and Maneb (Manganese ethylene-1,2-bisdithiocarbamate), the tin(IV)-sulfur bond in complex-6 (see Fig.2) reinforces its antifungal activity, but the toxic effect of this compound is probably due to by-products from decomposition in solution [27].<smiles></smiles>

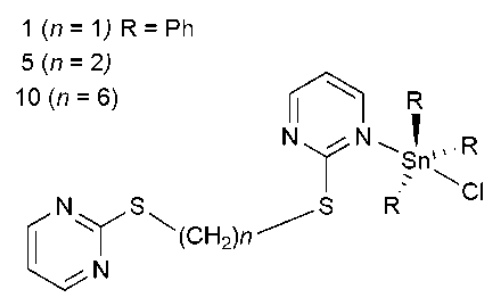

$9(n=6) \mathrm{R}=\mathrm{Ph}$

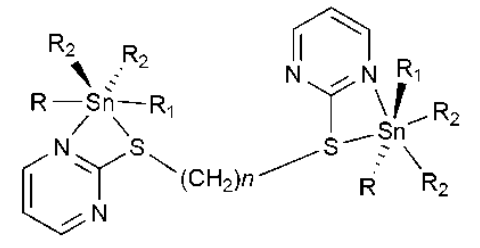

$\hat{\sigma}(n=2), R=R_{1}=C l, R_{2}=P h$ $11(n=6)$<smiles></smiles>

$$
2(n=1), \mathrm{R}=\mathrm{R}_{1}=\mathrm{Cl}, \mathrm{R}_{2}=\mathrm{Ph}
$$

Figure 2. Proposed structures of complex-1, 2, 5, 6, 9, 10 and 11 .
On the other hand, the tin(IV)-sulfur bond is not present in the active complexes 1, 2, 5, 9 and 10 (see Fig.2) according to the infrared spectroscopy [27]. In these compounds, the tin(IV) center is bonded to a nitrogen atom only. Consequently, this chemical bond is probably significant chemical feature to the fungi toxic effect of these organotin(IV) derivatives. Nevertheless, complex-13, a polymeric compound having the metal at the center of an octahedron as indicated by Mössbauer spectroscopy, was inactive regardless of the tin(IV)-nitrogen bond formation (see Fig.3) [28]. Because of this bond type and the polymeric character of 13 , this compound was expected to show antimicrobial activity as the oil based tin polymers [29-30]. As a concluding remark, the biochemical interaction between these organotin(IV) compounds and the phytopathogens appears to be intrinsically related to the formation of a tin(IV)-nitrogen bond and the trigonal bipyramidal geometry. This observation corroborates with the fact that this geometrical arrangement is associated with the best results of antifungal effect.

The acid character of the metal precursor - The organotin(IV) derivatives of bis(pyrimidin-2-ylthio)alkanes followed a fungi toxic pattern that correlates with the number of chlorine atoms bonded to the tin(IV) center at the metal precursor. This effect is shown in Graph 2 to a series of triphenyltin(IV) derivatives of $\mathrm{ptm}$. The same pattern is observed in the other $p t h$ - and pte-organotin(IV) derivatives.

The relationship between electronegativity and acid-base character of chemicals is recognized in the chemistry field. The chlorine atom $\left(\chi^{\mathrm{b}}=3.16\right)$ is more electronegative than the tin(IV) atom $\left(\chi^{\mathrm{b}}=1.96\right)$, according to Pauling $\left(\chi^{\mathrm{b}}, \mathrm{b}=\right.$ polarizability) [31].

By increasing the number of chlorine atoms attached to the tin(IV), which is already electron deficient due to its oxidation state, the electron density at this metal center is likely to reduce even more due to the bond polarizability.

In this situation, an enhancing of the tin(IV) Lewis acid character is predictable. The bioassay data in Graph 2 demonstrate the correlation of that to the fungicidal activity. As the acid character of the metal precursor decreases, upon coordination of the bis(pyrimidin-2-ylthio)alkanes, the more significant the fungicidal effect becomes for the phytopathogens. The increasing Lewis acid character 
corroborates with the inactivity of the trichloride and tetrachloridetin(IV) derivatives (3, 4, 7, 8, 12 and 13). Therefore the acid character of the metal center in combination with the antifungal data let to postulate that this chemical property has an influence on the biochemical interaction between phytopathogens tested and the tin(IV)-bis(pyrimidin-2-ylthio)alkanes derivatives.

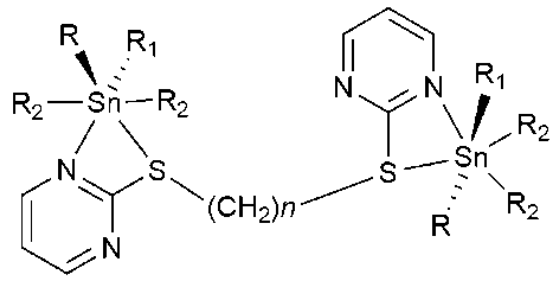

$$
\begin{aligned}
& 3(n=1), \mathrm{R}=\mathrm{Ph}, \mathrm{R}_{2}=\mathrm{R}_{1}=\mathrm{Cl} \\
& 7(n=2) \\
& 12(n=6) \\
& 4(n=1), \mathrm{R}=\mathrm{R}_{2}=\mathrm{R}_{1}=\mathrm{Cl} \\
& 8(n=2)
\end{aligned}
$$<smiles></smiles>

$13(n=6)$

Figure 3. Proposed structures of complex-3, 4, 7, 8, 12 and 13.

\section{Experimental}

The bioassay was conducted by the use of the filter paper transfer (A) and food poison (B) techniques [16]. The fungal species used were Fusarium semitectum, Aspergillus flavus, Aspergillus ochraceus and Colletotrichum gloesporioides. The conidia of the phytopathogens were produced on freshly prepared standard PDA (Potato-dextrose agar) containing 100 $\mathrm{mg} \mathrm{L}^{-1}$ of streptomycin sulphate to inhibit bacterial growth. The conidial suspension of each species was prepared by washing off the conidia from the agar surface, and then the concentration of conidia in the wash water was adjusted to $10^{4}$ $\mathrm{mL}^{-1}$.

In the filter paper transfer technique (A), a PDA aliquot of $10 \mathrm{~mL}$ was poured into sterile $9 \mathrm{~cm}$ plastic culture plates. The organotin(IV) derivatives were dissolved in methanol at concentrations ranging from 50 to $3000 \mathrm{mg} \mathrm{L}^{-1}$, and an aliquot of $10 \mu \mathrm{l}$ of the metal solution was imbibed into a $10 \mathrm{~mm}$ diameter sterile filter paper disc. The discs absorbed with methanol only were used as control. After evaporation of the methanol under a laminar flow hood, $10 \mu \mathrm{l}$ of the desired conidial suspension was placed at the center of the discs that were transferred to the PDA culture plates and incubated at 25 ${ }^{\circ} \mathrm{C}$. The presence or absence of fungal growth was examined after 48 hours. In case of no growth, the incubation period was extended to 7 days. The experiment was finished in triplicate, and repeated.

In the food poison technique (B), the methanol solution of the tin(IV) derivatives at the concentration of 80 and $400 \mathrm{mg}$ $\mathrm{L}^{-1}$ was mixed with cool molten PDA and then poured into culture plates. The control plate was prepared by adding an equivalent amount of methanol only in PDA. After solidification, the medium was spot seeded in the center of the plate by placing $10 \mu \mathrm{l}$ of the conidial suspension of the test fungus and then incubated for 8 days at $25{ }^{\circ} \mathrm{C}$. Subsequently the colony diameter was measured and the percentage growth ( $p g$ ) inhibition calculated by (1) where the diameter of the colony growth in the control plate is $x$, and $y$ is the diameter of that in the substance test plate.

$$
\operatorname{pg}(\%)=(x-y) 100 / x
$$

The bis(pyrimidin-2-ylthio)alkanes and the organotin(IV) derivatives were prepared and characterized by our research group [27, 28]. These compounds have the tin(IV) atom at the center of an octahedron as well as a trigonal bipyramidal arrangement., The pyrimidin-2-ylthioalkanes are coordinated by the monodentate, bridging bidentate and bridging tetradentate modes as shown in Fig. 1 and Fig. 2.

\section{Conclusions}

The best antifungal results were of the compounds having a tin(IV)-nitrogen bond in combination with a trigonal bipyramidal geometry. The bioassay data reveals that the microorganisms are vulnerable to the Lewis acid character of the organotin(IV)-bis(pyrimidin-2-ylthio)alkanes.

\section{Acknowledgments}

The authors would like to thank the Brazilian Agency CNPq for granting a scholarship to Fernanda A. Mendonça and FAPEMIG for financial support.

\section{References}

[1] A.E. Desjardins, H.K. Manandhar, R.D. Plattner, G.g. Manandhar, S.M. Poling, C.M. Maragos, Fusarium species from Nepalese rice and production of mycotoxins and gibberellic acid by selected species, Appl. Environ. Microbiol., 66, 1020-1025, 2000.

[2] B. Giray, G. Girgin, A.B. Engin, S. Aydin, G. Sahin, Aflotoxin levels in wheat samples consumed in some regions of Turkey, Food Control, 18, 23-29, 2007.

[3] B.T. Iamanaka, H.C.D. Menezes, E. Vicente, R.S.F. Leite, M.H. Taniwaki, Aflatoxigenic fungi and aflatoxins occurrence in sultanas and dried figs commercialized in Brazil, Food Control, 18, 454-457, 2007. 
[4] Saleemullah, A. Iqbal, I.A. Khalil, H. Shah, Aflatoxin contents of stored and artificially inoculated cereals and nuts, Food Chem., 98, 699-703, 2006.

[5] M. Zaccardelli, V. Balmas, C. Altomare, L. Corazza, C. Scotti, Characterisation of Italian Isolates of Fusarium semitectum from Alfafa (Mendicago sativa L.) by AFLP Analysis, Morphology, Pathogenicity and Toxin Production, Phytopathology, 154, 454-460, 2006.

[6] I. Pujol, J. Guarro, J. Gené, J. Sala, In-vitro antifungal susceptibility of clinical and environmental Fusarium spp. strains, J. Antimicrob. Chemother., 39, 163-167, 1997.

[7] M.D. Muller, H.P. Bosshardt, Degradation and residues of cyclohexyltin compounds in orchard soil following field application of cyhexatin, J. Agric. Food Chem., 38, 627-633, 1987.

[8] M. Gielen, Tin-based antitumour drugs, Coord. Chem. Rev., $151,41-51,1996$

[9] M. Gielen, H. Dalil, M. Biesemans, B. Mahieu, D. de Vos, R. Willem, Di- and tri-organotin derivatives of 3S,4S-3(R)-1-(tert-butyl-dimethylsilyloxy)ethyl -4- (R)-carboxyethyl 2-azetidinone: Synthesis, characterization and in vitro antitumour activity, Appl. Organomet. Chem., 13, 515-520, 1999.

[10] M. Kidwai, B. Dave, P. Misra, R.K. Saxena, M. Singh, Novel synthetic approach for antifungal and antibacterial organotin compounds, Inorg. Chem. Commun., 3, 465-468, 2000.

[11] A.K. Mishra, N. Manav, N.K. Kaushik, Organotin(IV) complexes of thiohydrazones: synthesis, characterization and antifungal study, Spectrochimica Acta Part A: Molecular and Biomolecular Spectroscopy, 61, 3097-3101, 2005.

[12] M. Nath, S. Pokharia, G. Eng, X.Q. Song, A. Kumar, M. Gielen, R. Willem, M. Biesemans, New trimethyl tin(IV) derivatives of dipeptides: synthesis, characteristic spectral studies and biological activity, Appl. Organomet. Chem., 18, 460-470, 2004.

[13] M. Roy, S.S. Devi, S. Roy, C.B. Singh, K.S. Singh, Synthesis, characterization, crystal structures and in vitro antimicrobial activities of triorganotin(IV) complexes of azo-dicarboxylates, Inorg. Chim. Acta, 426, 89-98, 2015.

[14] R. Willem, M. Biesemans, M. Boualam, A. Delmotte, A. Elkhloufi, M. Gielen, (Diorgano)halogeno(2,6-pyridinedicarboxylato)stannates synthesis, characterization and in-vitro antitumor-activity., Appl. Organomet. Chem., 7, 311-317, 1993.

[15] Y. Yu, H. Yang, Z.-W. Wei, L.-F. Tang, Synthesis, Structure, and Fungicidal Activity of Organotin Dithiocarbamates Derived from Pyridinamines and Aryl Diamines, Heteroat. Chem., 25, 274-281, 2014.

[16] O.D. Dhingra, J.B. Sinclair, Basic Plant Pathology Methods, 2nd ed., CRC Lewis Publishers., Boca Raton, Florida, 1995.

[17] O.M. Walsh, M.J. Meegan, R.M. Prendergast, T. AlNakib, Synthesis of 3-acetoxyazetidin-2-ones and 3-hydroxyazetidin-2-ones with antifungal and antibacterial activity, Eur. J. Med. Chem., 31, 989-1000, 1996.

[18] R. Fioravanti, M. Biava, G.C. Porretta, C. Landolfi, N. Simonetti, A. Villa, E. Conte, A. Portapuglia, Research on antibacterial and antifungal agents .11. Synthesis and antimicrobial activity of N-heteroaryl benzylamines and their Schiff-bases, Eur. J. Med. Chem., 30, 123-132, 1995.

[19] A. Saxena, J.P. Tandon, A.J. Crowe, Synthesis and spectroscopic studies on organotin derivatives of biologically active Schiff bases, Polyhedron, 4, 1085-1089, 1985.

[20] W. Rehman, M.K. Baloch, B. Muhammad, A. Badshah, K.M. Khan, Characteristic spectral studies and in vitro antifungal activity of some Schiff bases and their organotin(IV) complexes, Chin. Sci. Bull., 49, 119-122, 2004.

[21] B. Sarkar, B. Choudhury, M.S. Sarma, S.K. Kamruddin, A.K. Choudhury, A. Roy, Potentiality of organotin(IV) compounds in the control of foliar blight disease of wheat (Triticum aestivum) caused by Bipolaris sorokiniana, Arch. Phytopathol. Plant Prot., 44, 1754-1769, 2011.

[22] N. Sonika, R. Malhotra, Synthesis and structural studies on penta and hexa coordinated organotin (IV) complexes of alkyl pyruvate aroyl hydrazones, Der Pharma Chem., 3, 305-313, 2011.

[23] P. Novak, A. Lycka, I. Cisarova, V. Buchta, L. Silva, L. Kolarova, A. Ruzicka, J. Holecek, Strucutre of the Azo dye organotin(IV) compounds containing a $\mathrm{C}, \mathrm{N}$-chelating ligand, part II, and their in vitro antifungal acitivity, Appl. Organomet. Chem., 19, 500-509, 2005.

[24] H.L. Singh, A.K. Varshney, Synthesis and characterization of coordination compounds of organotin(IV) with nitrogen and sulfur donor ligands, Appl. Organomet. Chem., 15, 762-768, 2001.

[25] S.-G. Teoh, S.-H. Ang, S.-B. Teoh, H.-K. Fun, K.-L. Khew, C.-W. Ong, Synthesis, crystal structure and biological activity of bis(acetone thiosemicarbazone-s)dichlorodiphenyltin(IV), Journal of the Chemical Society Dalton Transactions, 465-468, 1997.

[26] H.M. Parekh, M.N. Patel, Preparation of Schiff's base complexes of $\mathrm{Mn}(\mathrm{II}), \mathrm{Co}(\mathrm{II}), \mathrm{Ni}(\mathrm{II}), \mathrm{Cu}(\mathrm{II}), \mathrm{Zn}(\mathrm{II})$, and $\mathrm{Cd}(\mathrm{II})$ and their spectroscopic, magnetic, thermal, and antifungal studies, Russ. J. Coord. Chem., 32, 431-436, 2006.

[27] R.C.R. Chagas, J.R.d.S. Maia, V.P. Ferraz, Synthesis and characterization of organotin(IV) derivatives of ambidentate ligands containing nitrogen and sulphur donor atoms, Main Group Met. Chem., 34, 131-137, 2011.

[28] R.C.R. Chagas, J.R.d.S. Maia, J.D. Ardisson, A. Gurgel, Characterization of organotin(IV) derivatives of 1,6-bis(pyrimidin-2-ylthio)hexane by Mossbauer spectroscopy, Trends Appl. Spectrosc., 9, 67-74, 2012.

[29] A. Ahmad, A. Khan, N.P. Bharathi, A.A. Hashmi, L.A. Khan, N. Manzoor, Impaired ergosterol biosynthesis mediated fungicidal activity of oil based tin polymer, Med. Chem. Res., 20, 1141-1146, 2011.

[30] N.P. Bharathi, M. Alam, S. Shreaz, A.A. Hashmi, Synthesis, Characterization and Biological Studies of Oil Based Tin Polymer, J. Inorg. Organomet. Polym. Mater., 19, 459-465, 2009.

[31] J.E. Hueeye, E.A. Keiter, R.L. Keiter, Inorganic Chemistry Principles of Structure and Reactivity, 4 ed., HarperCollins College Publishers, New York, 1993. 